\title{
Meta
}

Journal des traducteurs

Translators' Journal

\section{Ear Voice Span in English into Korean Simultaneous Interpretation}

\section{Tae-Hyung Lee}

Volume 47, numéro 4, décembre 2002

URI : https://id.erudit.org/iderudit/008039ar

DOI : https://doi.org/10.7202/008039ar

Aller au sommaire du numéro

Éditeur(s)

Les Presses de l'Université de Montréal

ISSN

0026-0452 (imprimé)

1492-1421 (numérique)

Découvrir la revue

Citer cet article

Lee, T.-H. (2002). Ear Voice Span in English into Korean Simultaneous Interpretation. Meta, 47(4), 596-606. https://doi.org/10.7202/008039ar

META

Résumé de l'article

L'analyse informatique d'environ 800 phrases d'une interprétation simultanée de l'anglais au coréen a permis de savoir que le décalage, par l'interprète, est de 3 secondes en moyenne. Des analyses statistiques ont montré que des données telles que la longueur des phrases anglaises, le nombre de mots par minute ou les pauses avaient un impact sur l'importance de ce décalage qui, lui-même, influe directement sur le travail de l'interprète. Ainsi quand l'écart s'accroît, l'interprète coréen peut avoir à augmenter son débit pour suivre l'orateur. S'il est trop long, cela nuit non seulement à la phrase en cours de traduction mais aussi à celle qui la suit. 


\title{
Ear Voice Span in English into Korean Simultaneous Interpretation
}

\author{
TAE-HYUNG LEE \\ Hanyang University, Ansan, Korea
}

\begin{abstract}
RÉSUMÉ
L'analyse informatique d'environ 800 phrases d'une interprétation simultanée de l'anglais au coréen a permis de savoir que le décalage, par l'interprète, est de 3 secondes en moyenne. Des analyses statistiques ont montré que des données telles que la longueur des phrases anglaises, le nombre de mots par minute ou les pauses avaient un impact sur l'importance de ce décalage qui, lui-même, influe directement sur le travail de l'interprète. Ainsi quand l'écart s'accroît, l'interprète coréen peut avoir à augmenter son débit pour suivre l'orateur. S'il est trop long, cela nuit non seulement à la phrase en cours de traduction mais aussi à celle qui la suit.
\end{abstract}

\section{ABSTRACT}

A computer-aided analysis of some 800 sentences taken from English into Korean simultaneous interpretation(SI) revealed that the average ear-voice-span (EVS) is 3 seconds. Statistical analysis showed that speaker variables, including the length of original English sentence, wpm, and pauses affected the length of EVS, and the EVS, in turn, affected the interpreter variables. When the EVS is lengthened, Korean interpreters increased the speed of their target language (TL) delivery to catch up with the speaker. Long EVS had a negative effect, not only on the quality of the sentence being processed, but also on the processing of the following sentence.

\section{MOTS-CLÉS/KEYWORDS}

EVS, simultaneous interpretation, Korean, quality, information processing

\section{INTRODUCTION}

The EVS, or lag time between the moment an incoming message is perceived by a conference interpreter and the moment the interpreter produces his translation of the segment, is one of the few observable variables in SI study. The importance of this variable is that it can be easily quantified for research on SI processing. Thus, EVS has been one of the most outstanding variables for corpus analysis and time management of SI.

During this short EVS, interpreters carry out numerous concurrent information processing, including comprehension of incoming source language (SL), converting, planning TL and uttering TL. Even while uttering the TL, interpreters are believed to monitor their own rendition. As a deep scrutiny on the SI processing should be based on the actual SI products, this study will examine real-life English into Korean SI data to examine the information processing of SI where interpreters are hearing L2 (English) and uttering L1 (Korean). This study explores the following points.

a. Will the speaker variables affect the length of EVS?

b. Will the length of EVS affect the interpreter variables?

c. Will the length of EVS affect the quality of interpreted Korean rendition?

Meta, XLVII, 4, 2002 


\section{MATERIALS AND PROCEDURES}

Thirty audiotapes of English speeches and 30 Korean SI by professional conference interpreters were chosen for the computer-aided analysis. Those SI were mainly for live coverage on TV and the length of each SI ranged from 3 to 5 minutes. A total of 555 original English sentences were included; however, only 407 sentences were simultaneously interpreted into Korean. As in the case of Barik (1973), only interpreted original sentences were analyzed, and those English sentences were excluded whose Korean interpretation was not carried out. This made the total number of analyzed English and Korean sentences 814. Eight professional conference interpreters were involved in this analysis. Their mother tongue was Korean, and English was their strongest passive language. All of them graduated from the Graduate School of Interpretation and Translation, Hunkuk University of Foreign Studies in Korea. The use of "real-life" SI data by professional interpreters precludes the problem that might stem from using student interpreters and experimental materials (Gile 1995).

The audio of the speeches and SI were saved into a PC equipped with voiceediting software that can measure up to 1 millisecond. A total of 60 wave files, 30 original speeches and 30 interpretations, were obtained. Next, the English and Korean interpretations were transcribed and 30 English and 30 Korean interpretation texts were produced.

While analyzing the wave file, the speakers' wave files and interpreters' versions were shown on a computer screen at the same time, one in the upper window and the other in the lower window. It allowed the researchers to "watch" a two-track recording of speaker's and interpreter's performances. As Alexeva (1991) pointed out, the study of two-track recording can be "more objective and reliable data." Actual voice could be played back from the waveform on the screen while measuring the length of EVS and the length of each pause. Silences exceeding 250 msec were judged as pauses following the criteria proposed by Goldman-Eisler (1973). After measuring the length of each pause, it was marked on the transcription of both the original and interpretation scripts. In the process, EVS was measured in seconds rather than the number of words to see the relationship with other temporal aspects.

Investigated were the linguistic factors in the original English speech and those in interpreted Korean speech. Speaker variables included the number of English syllables, speaking time, syllables per minute, speech proportion (SP), and betweensentence pauses. Since interpreter factors alone were meaningless, those interpreter variables were compared for the English variables and interpreter/speaker ratio was calculated. The length of EVS, EVS/the length of a sentence, the difference of EVS in both speaking and listening portion and listening alone portion were scrutinized. Simultaneously interpreted Korean sentences were compared for accuracy with the original English sentence based on word correspondence.

\section{EVS IN SIMULTANEOUS INTERPRETATION}

Many scholars report the high processing load of SI (Moser 1997) including the higher recall after listening alone than SI or shadowing (Lambert 1988, DARO and Fabbro 1994, Isham 1994). A longer EVS found in SI than in shadowing (De Groot 1997) also shows the heavy information processing by the interpreter. The fact that 
the interpreter cannot control the flowing sequence of a message, while readers can pause and go back for further understanding, makes SI particularly difficult. These studies show that "interpreters may not listen in the same way as those subjects told to listen in silence" (Lambert 1988). Under these constraints, interpreters mobilize topdown processing using their background knowledge and take advantage of the redundancy of language. Actually this is what people do when they listen to speech as Slobin (1979) explained: "when you listen to speech you try to make sense of it in terms of what you know about the speaker and the situation and world in which you live."

Thanks to the anticipation based on top-down processing, the interpreter can utter his TL before the end of the incoming sentence. EVS, therefore, can be defined as the minimum time needed by an interpreter for information processing under heavy cognitive processing. Kade (1971) said that the optimal moment for the interpreter to start uttering TL is immediately after all syntactic and semantic ambiguities in the unit have been resolved. Ideally the EVS should be as short as the prevailing circumstances permit (de Groot 1997). For interpreters, however, the heavy cognitive processing inevitably lengthens the EVS. As Setton (1999) pointed out, "interpreters are not at liberty to wait indefinitely for possible disambiguating information downstream." This is mainly due to the fact that our raw memory for strings of words is not nearly large enough to accommodate the SI task (MacWhinney 1997). When EVS increases, the more information the interpreter should store in his short-term memory. Then the memory load will become heavier as the EVS further increases. Successive incoming of the following messages also makes it difficult for interpreters to wait long before uttering TL. If he waits too long for a complete processing of the sentence, lagging far behind the speaker, the processing of the following sentences might be impeded.

Concerning the length of EVS, Goldman-Eisler (1972) argues that the minimum EVS sequence is the NP+VP where the VP is a crucial part of the information required. Adamowicz (1989) also reports prevalent EVS was NP or VP for both Polish and English. Therefore, EVS is dependent on syntactic constituents, that is, interpreters segmented the incoming message at linguistically appropriate places before delivering them (Barik 1975). Barik (1973) who measured the EVS in seconds rather than words found that the average EVS is in the range of 2 to 3 seconds. Schweda (1987) says EVS is 5 to 10 words or several seconds. Lederer (1978) observed the delay to be between 3 and 6 seconds.

\section{EVS IN ENGLISH INTO KOREAN SIMULTANEOUS INTERPRETATION}

Proper understanding of English speech (L2) by the Korean conference interpreter is a key to ensuring satisfactory SI. As Weller (1991) pointed out, comprehension of the source text is the most difficult and important stage. Uttering TL with an EVS means that the interpreter has succeeded in the processing up to this point without regard to the quality of the comprehension of the segment.

As Korean interpreters are listening to L2, they might encounter many difficulties that they would not encounter when listening to L1. This is due to the fact that language processing is less efficient in a second language (Long 1978). Their memory capacity for L2 is smaller than for L1 (Call 1985, Griffith 1990), and linguistic rules 
for English in their long-term memory will be weaker than that of a native speaker of English.

The syntactic difference between English and Korean poses additional difficulty for Korean interpreters. Goldman-Eisler (1972) explains the lengthened EVS in the SI from German in which verbs frequently follow the object. Barik (1975) also points out the same difficulty, and Gile (1997) reported that differences between syntactic structure of the SL and the TL could increase memory processing requirements. Therefore, interpreters engaging in English into Korean SI might suffer from the above-mentioned dilemmas since Korean is an SOV language like German.

Another unique difficulty English into Korean interpreters are facing is that Korean needs more words than English to convey the same amount of information (Lee 1999a). To conduct an omission-free English into Korean SI, Korean interpreters would have to utter 310 syllables per minute in order to interpret $160 \mathrm{wpm}$ of English speech. In this study, the average speed of English speech exceeded $200 \mathrm{wpm}$, which is well beyond the ideal speed for interpretation, 100-120wpm by Seleskovitch (1978), or 100 wpm by Barik (1975).

When the original English speech contains academic and formal expressions, Korean interpreters should come up with the same language level in the Korean interpretation rendition. The problem here is that abstract and low frequency words would not be translated so quickly as concrete and high frequency words (de Groot 1997). Therefore, retrieving such Korean equivalents will pose a challenge for interpreters who are under extreme time pressure, and the EVS will be lengthened. This kind of producing elegant reformulation may result in an individual processing capacity deficit (Gile 1997). This becomes serious when we consider Obana's (1993) contention that even native speakers of Japanese produce errors of pragmatic collocation and stylistic constraints in their interpretation from English into Japanese.

In short, Korean interpreters would have to convert the underlying meaning at deep structure level to produce TL sounding clear and natural to the audience during this short EVS.

\section{RESULTS}

A statistical analysis of 814 English and Korean sentences revealed that the average EVS in English into Korean SI is 3 seconds. T-tests were carried out between the groups of sentences with EVS longer than 4 seconds and the other group with EVS shorter than 2 seconds. This was to examine if there is any difference in the interpreter and speaker variables between two groups.

A t-test indicated that the speaker's syllables of the group of EVS above 4 seconds (24.1 syl) were statistically larger than the group of EVS below 2 seconds (16.5 syl, $\mathrm{p}=0.00$ ). The speakers' speaking time of the long EVS group was statically longer (5.7 $\mathrm{sec})$ than the short EVS group (3.8 sec $\mathrm{p}=0.00)$. Between-sentence pauses of the long EVS group $(0.63 \mathrm{sec})$ were smaller than with the short EVS group $(0.84 \mathrm{sec}, \mathrm{p}=0.09)$. Speakers' syllables per minute of the long EVS group were lower $(280 \mathrm{spm})$ than of the short EVS group ( $303 \mathrm{spm}, \mathrm{p}=0.06$ ). The long EVS group showed lower SP of the speaker $(0.88)$ than the short EVS group $(0.92, \mathrm{p}=0.028)$.

Syllables of the interpreter of the long EVS group was larger (29 syl) than the short EVS group (26 syl, p=0.05). Syllables I/S ratio of the long EVS group was lower 
(1.34) than the short EVS group (1.73, $\mathrm{p}=0.00)$. Significant difference in speaking time I/S ratio was found between the long EVS group (1.11) and the short EVS group (1.61, $\mathrm{p}=0.00)$. Syllables per minute I/S ratio of the long EVS group was higher (1.35) than the short EVS group (1.18, $\mathrm{p}=0.003)$. SP I/S ratio of the long EVS group was higher (1.08) than the short EVS group $(0.98, \mathrm{p}=0.015)$. The EVS of the listening only portion was shorter $(2.46 \mathrm{sec})$ than of the listening and speaking portion $(3.25$ sec, $\mathrm{p}=0.00$ ).

The quality of sentences with EVS above 4 seconds was lower (66.8\%) than those with EVS below 2 seconds $(82.6 \%, \mathrm{p}=0.00)$. The EVS/sentence ratio of longer EVS group was higher (1.2) than that of the shorter group $(0.49, \mathrm{p}=0.00)$. The EVS of sentences preceded by sentences with EVS above 4 seconds was longer $(3.83 \mathrm{sec})$ than that preceded by those with EVS below 2 seconds $(2.85 \mathrm{sec}, \mathrm{p}=0.002)$. The quality of the sentences preceded by the sentences with long EVS was poorer $(38.6 \%)$ than the segments following the sentences with short EVS $(60.0 \%, \mathrm{p}=0.00)$.

\section{DISCUSSION}

\subsection{EVS and speaker variables}

In English into Korean SI, the speakers' factors, including the number of English syllables, speaking time, syllables per minute, SP, and between-sentence pauses, are independent variables that influence EVS that is a dependent variable. In other words, an EVS is first set by the speaker variables, and the EVS, in turn, affects interpreter variables. The fact that the average length of EVS in English into Korean SI is 3 seconds is in close agreement with the study by Barik (1973) who found the average EVS to be in the range of 2 to 3 seconds.

The results showed that long English sentences invited longer EVS and short sentences produced shorter EVS. A possible explanation for this is that longer English sentences are syntactically more complex than shorter ones, and interpreters would have to wait for a time to have a minimum amount of information for TL delivery. Sheweda-Nicholson (1987) says some difficult or complicated material may require a longer EVS, while more straightforward parts can be processed with a shorter EVS.

Longer between-sentence pauses shortened EVS and the reverse was true. This implies that the long pauses between sentences reduce the hard concurrent processing of listening and speaking by the interpreter, allowing proper information processing (Lee 1999c). Pauses between original sentences mean that the incoming original message is suspended among many concurrent processes an interpreter has to undertake. Barik (1973) said, "This permits interpreters to reduce the extent to which he has to both speak and listen at the same time, which undoubtedly represents very complex processing behavior." Barik (1975) also reported that pauses in speakers' delivery would seem to be an important factor affecting translation performance. The importance of the role of pauses for interpreter processing was also studied by Gerver (1976). It is clear that Korean interpreters benefit from pauses to shorten their EVS and process the incoming message quickly.

Regarding speech rates of the speaker and EVS, Gerver (1974) asserted the EVS and density of original speech are not interrelated. On the other hand, Barik (1973) who examined English-French SI data found that interpreters lagged further and 
further behind when input rate increased. De Groot (1997) also reported that interpreters lengthened the EVS when density of original speech increases. In the case of English into Korean SI, however, high speech rate and SP of the speaker reduced EVS while EVS was lengthened when the speech rate and SP decreased. If Korean interpreters increase their EVS under the high original speech rate and SP, it is true that they might understand SL better than with short EVS. The next sentences, however, will stream down at high speed while the interpreter is working on the previous sentence, potentially overloading his limited processing capacity. In other words, the amount of information rushing into the interpreter's ear is heavier than with a slow input rate. This is well illustrated by de Groot(1977) who argued that high input rate means the time span over which the words are presented in the input is relatively short. This will make the input more difficult for the interpreter to process than with slower input. Inevitably, parts of the information will be lost if the interpreter cannot process the incoming message quickly enough. High SP of the speaker, in particular, will expand the portion of concurrent speaking and listening on the part of the interpreter. Shortened pauses in the original speech resulting from high SP will levy a heavy processing constraint on the interpreter. In this situation, the interpreter will feel that he cannot maintain the current EVS lest the processing requirements exceed the total capacity of the interpreter. To escape this dilemma, the Korean interpreter seems to take the strategy of shortening the EVS in order to process the incoming message quickly so as not to lose too much and to secure room in his capacity. When we regard information density as syntactic complexity as well as sentence length, it would be correct to assume that EVS will increase. On the other hand, if the density means only the temporal aspect, including wpm and SP of the speaker, EVS cannot be increased in English into Korean SI for the reasons mentioned above. Therefore, the speaker variables were proved to influence the length of EVS.

\subsection{EVS and interpreter variables}

Regarding the relationship between EVS and interpreter variables, the latter are dependent variables being influenced by EVS. Once the interpreter begins to utter TL after a certain EVS, the remainder of the interpreter's factor are determined.

Longer EVS was followed by longer sentences by the interpreter than that of shorter EVS. This shows the dependency of SI on the nature of the original speech. As Gile (1995) pointed out, interpreters have to follow the path chosen by the source-language speaker. The already long original sentences needed many Korean syllables to convey the same amount of meaning.

The short EVS increased syllable I/S ratio and speaking time I/S ratio. This shows that the interpreter with short EVS can utter more words and speak longer than the speaker. As EVS, among other things, means the interpreter has completed processing some parts of the sentence, short EVS indicates that the processing was smooth and speedy. This is because he can render the translated version without being interrupted by the following original sentences since he began uttering TL early. With long EVS, on the other hand, the processing of the sentence he is working on and the next sentence will overlap. So he has to finish the sentence as quickly as possible to decrease the overlapping portion and to alleviate the information processing 
constraints. This in turn reduces the number of syllables and speaking time by interpreter relative to speaker.

The fact that long EVS increased interpreter's wpm and SP implies that the interpreter with long EVS for some reasons speaks fast to catch up with the speaker so as not to lose too much. Then the pauses in TL rendition will be shortened and SP increased. This was well analyzed by Van Dam (1986:61) as follows:

When, for whatever reason, we fall behind the speaker, the amount of information backlog is proportional to the increasing distance between the speaker and the interpreter. In other words, the further behind we fall, the more information we must store in short-term memory. And the greater the memory load, the greater the stress under which we work. We therefore catch up with the speaker as quickly and unobtrusively as possible, but without losing any substantive portion of the message.

Lee (1999b) also confirmed this kind of "cramming TL" by interpreters engaging in English into Korean SI. To summarize the present section up to this point, when the Korean interpreter begins his TL early, he speaks for a longer period of time uttering more words while he speeds up his TL without long pauses when he lags far behind the speaker.

It was found that Korean interpreters began their TL utterance earlier in the listening alone situation than in the concurrent listening and speaking portion. A listening alone situation means the interpreter stopped uttering his TL among many concurrent information processing tasks. The reason for this short EVS in a listening alone situation would be that the interpreter, during a listening alone portion, could attribute the attention that would have been paid to uttering TL to processing incoming message. In this situation, his processing will become more efficient than in the concurrent listening and speaking portion.

Since the average length of EVS in this study was 3 seconds and the average between-sentence pauses by the interpreter was 1.2 second, this means that the interpreter stops uttering his TL and attends totally to processing SL for 1.2 seconds which is $40 \%$ of the total length of the original sentence.

Therefore, this clearly demonstrates that the length of EVS in English into Korean SI affects the interpreter variables.

\subsection{EVS and accuracy of SI}

Longer EVS induced poor sentence quality and EVS/sentence ratio did the same thing. This clearly shows that the length of EVS influences the quality of SI in some way. Concerning the length of EVS and the quality of SI, Moser (1997) reported that expert interpreters tend to opt for a longer EVS as they have a more comprehensive, micro view of the evolving message. On the other hand, Barik (1973) argued that the "interpreter will perform better in terms of omitting less material if he does not lag too far behind the speaker."

If we apply these arguments to the results obtained in this study, it would be safe to assume that longer EVS implies overloading of information processing by the Korean interpreter as evidenced in the relation between SP and EVS. In addition to the intrinsic difficulty of interpreting long sentences, a possible explanation for this phenomenon would be the syntactic difference between English-Korean combination. While listening to SVO English and interpreting it into SOV Korean, the interpreter 
must hold the English verb that he perceived early on until he utters TL. This will impose some constraints on memory and impede the whole information processing. For example, if a long noun clause were used as the object of a verb, it would be very risky for the interpreter to wait until the end of the noun clause while holding the main verb in his memory. Gile (1997: 200) explains this situation as follows.

If additional processing capacity is then allocated to the memory effort, this may in turn deplete the capacity available for listening and analysis effort, leading to a potential problem in the comprehension of another SL speech segment.

To be more specific, the average length of 407 English sentences analyzed in this paper was 4.5 seconds, containing 13.3 words each. With a speed of $200 \mathrm{wpm}$, an average EVS of 3 seconds means $66 \%$ of the sentence, 8 words, was already perceived by the interpreter before beginning TL uttering. In this context, further lagging behind the speaker would deplete the memory capacity and damage the quality of the English into Korean SI. Zahner (1990) says human short-term memory can store a limited amount of information and needs to be refreshed at regular intervals.

Another factor that makes lagging too far impossible is that in SI, unlike consecutive interpretation, the successive message is being overflowed to interpreter at the speed set by the speaker, regardless of interpreter's processing capacity. Therefore, if the interpreter tries to lag far behind the speaker for complete understanding of the sentence, the next sentence will be flowing in and the EVS will exceed the length of one sentence. Considering the fact that Korean interpreters are listening to L2, their information processing will be overloaded as they have to process the second sentence while comprehending the first sentence. To avoid this dilemma, Korean interpreters in this study seemed to utter TL as early as possible to secure a minimum capacity for next incoming messages and to avoid extreme multi-processing. The longer EVS group which showed EVS longer than 4 seconds seemed to fail to take the above-mentioned strategy and produced low quality TL sentences which did not receive their deserved attention.

When the EVS is extended, there might be a long pause in the SI as the interpreter stops uttering TL while paying all his attention to listening to SL. In that case, the audiences at international conferences assume any silence in SI reflects a loss of information (Dejean 1990). Moser (1996) reports that nearly 90\% of users of conference interpretation found the interpreter's long pauses and lagging far behind the original speech irritating. Therefore, it becomes clear that interpreters cannot increase their EVS as they would like. But following too close to the original speech might produce word-for-word translation and may lead to a faulty translation of abstract words that would require a costly correction (De Groot 1997). In this context, maintaining optimum EVS would be key to ensure quality SI.

The relation between EVS and accuracy of SI also neatly explains the accuracy discrepancy between the listening alone situation and concurrent listening and speaking portion. Lee (1999b) reported that the accuracy of the concurrent listening and speaking portion was poorer than of the listening alone portion. In this study, the EVS of concurrent listening and speaking portion was proved to be longer than that of the listening alone portion. One of the factors responsible for this poor quality of concurrent listening and speaking portion will be the long EVS of the portion.

Another new finding was that long EVS also adversely influences both the EVS and quality of the next sentence as well. The EVS of sentences preceded by sentences 
with EVS above 4 seconds was longer than that preceded by those with EVS below 2 seconds. And the quality of the sentence preceded by the sentence with long EVS was lower than the sentence following the sentence with short EVS. This clearly reaffirms the above-mentioned points and shows the importance of maintaining proper EVS in SI. When the interpreter lags too far behind, the quality of that sentence and the next sentence are both sacrificed. This confirms the fact that the length of EVS affects the quality of interpreted Korean rendition.

\section{CONCLUSION}

It was found that the average length of EVS in English into Korean SI in this study was 3 seconds. This EVS, one of the most noticeable variables among temporal aspects, is a minimum time for interpreters to carry out many concurrent information processing tasks with limited capacity.

EVS in English into Korean SI was influenced by speaker variables and the length of English sentences, and between-sentence pauses increased the EVS. Unlike the previous studies on Indo-European SI, high speech rate and SP of the original English sentences in this study reduced the EVS. Conference interpreters engaging in English into Korean SI in this study are believed to shorten EVS and utter Korean TL quickly so as to reduce the memory load and adverse effects on the processing of the next sentence. Interpreter variables were also affected by the EVS as the long EVS increased interpreter's wpm and SP. Long EVS, however, decreased syllables I/S ratio, and speaking time I/S ratio. The quality of the sentences following short EVS was better than sentences with long EVS. This was attributable to the syntactic difference between Korean and English and interpreter's effort to stay close to the speaker to lessen memory load and to decrease pauses in their TL delivery. Once the interpreter lagged too far behind the speaker, not only the quality of the sentence he was working on, but also that of the following sentence was sacrificed.

These findings can be applied to interpreter training in that interpreters should understand the nature and the cause of EVS to take proper strategies in English into Korean SI. These strategies will include distribution of the limited attention of interpreter to each processing activity including comprehension, memory, converting, planning, and uttering. Since this fluctuating capacity sharing heavily taxes the limited processing resources of the simultaneous interpreter (de Groot 1997), proper management of processing capacity is very important to guarantee quality SI (Gile 1995). Among the concurrent processings, maintaining optimal EVS is extremely important since too short EVS might end up with a clumsy TL due to lack of comprehensive understanding of the source text, while too long EVS will reduce the quality of the sentence. As repeatedly emphasized, this is important because failing to keep proper EVS influences not only the sentence being processed, but also the incoming segment. Therefore, a certain language-specific strategy reflecting the syntactic difference between two languages should be mobilized. One of them would be as Uchiyama (1991) suggested, for several relative clauses in one English sentence, to interpret one clause after another to lessen memory load.

Coupled with these, anticipation (Setton 1999), chunking (Barik 1975) and background knowledge will be necessary. Zahner (1990) says good preparation activates long-term memory and improves the whole speed of processing. With the 
knowledge of the SL and TL, understanding of the subject matter, the interpreters' processing mechanism will become efficient and EVS will be shortened. This application of these strategies should be automated since extra effort is required for a controlled process, while it may not be necessary when it becomes an automatic task (DARO and Fabbro 1994). This type of practical training based on the theory of EVS will greatly contribute to improving the quality of English into Korean SI.

This work was supported by a research grant from Hanyang University, Korea, made in the program year of 2001 .

\section{REFERENCES}

Adamowicz, A.(1989): “The Role of Anticipation in Discourse: Text Processing in Simultaneous Interpreting," Polish Psychological Bulletin, 20, pp. 153-160.

Alexieva, B.(1989): “Analysis of the Simultaneous Interpreter's Output," In P. Nekeman (Eds.) Proceedings of the 11th World Congress of FIT, pp. 484-488.

BARIK, H.C. (1973): “Simultaneous Interpretation: Temporal and Quantitative Data," Language and Speech, 16-3, pp. 237-270.

- (1975): “Simultaneous Interpretation: Qualitative and Linguistic Data," Language and Speech, 18-3, pp. 272-297.

Call, M.E. (1985): "Auditory Short-Term Memory, Listening Comprehension, and the Input Hypothesis," TESOL Quarterly, 19-4, pp. 765-781.

Darò, V. and Fabbro, F. (1994): "Verbal Memory During Simultaneous Interpretation: Effects of Phonological Interference," Applied Linguistics, 15-4, pp. 365-381.

De Groot, A. M. B. (1997): “The Cognitive Study of Translation and Interpretation," In J. H. Danks, G. M. Shreve, G.M. Fountain and M.K. McBeath (Eds.), Cognitive Processes in Translation and Interpreting, London: Sage Publications, pp. 25-56.

Dejean Le Feal, K. (1990): "Some Thoughts on the Evaluation of Simultaneous Interpretation," In D.M. Bowen (Eds.), Interpreting-Yesterday, Today, and Tomorrow: American Translators Association Scholarly Monograph Series Vol. IV, New York: State University of New York at Binghamton, pp. 154-160.

Gerver, D. (1974): "Simultaneous Listening and Speaking and Retention of Prose," Quarterly Journal of Experimental Psychology, 26, pp. 337-341.

- (1976): “Empirical Studies of Simultaneous Interpretation: A Review and a Model," In R. W. Brislin (Ed.), Translation, Applications and Research, New York: Gardner Press, pp. 165-207.

Gile, D. (1995): Basic Concepts and Models for Interpreter and Translator Training. Amsterdam: John Benjamins Publishing Co.

- (1997): “Conference Interpreting as a Cognitive Management Problem," In J.H. Danks, G.M. Shreve, G.M. Fountain and M.K. McBeath (Eds.) Cognitive Processes in Translation and Interpreting, London: Sage Publications, pp. 196-214.

Goldman-Eisler, F. (1972): "Segmentation of Input in Simultaneous Translation," Journal of Psycholinguistic Research, 1-2, pp. 127-140.

- (1973): Psycholinguistics: Experiments in Spontaneous Speech, London: Academic Press Inc.

Griffith, R.(1990): "Speech Rate and NNS Comprehension: A Preliminary Study in Time-Benefit Analysis," Language Learning, 40-3, pp. 311-336.

Isham, W.P. (1994): "Memory for Sentence After Simultaneous Interpretation: Evidence Both for and against Deverbalization," In S. LAmbert and B. Moser-Mercer (Eds.), Bridging the gap: Empirical Research in Simultaneous Interpretation, Amsterdam: John Benjamins Publishing Co, pp. 191-212.

Kade, O. and C. Cartellieri (1971): "Some Methodological Aspects of Simultaneous Interpreting," Babel, 17-2, pp. 12-16. 
Lambert, S. (1988): "Information Processing Among Conference Interpreters: A Test of the Depth-of-Processing Hypothesis," META, 33-3, pp. 377-387.

Lederer, M. (1978): "Simultaneous Interpretation: Units of Meaning and Other Features," In D. Gerver and H. W. Sinaiko (Eds.), Language Interpretation and Communication, New York: Plenum Press, pp. 323-332

Lee, T. (1999a): "Speech Proportion and Accuracy in English into Korean Simultaneous Interpretation," META, 44-2, pp. 260-267.

— (1999b): "Simultaneous Listening and Speaking in English into Korean Simultaneous Interpretation," META, 44-4, pp. 560-572.

— (1999c): "Pauses in English into Korean Simultaneous Interpretation," (in Korean) Conference Interpretation and Translation, 1, pp. 123-144.

Long, J. and Harding-Esch, E. (1978): "Summary and Recall of Texts in First and Second Languages: Some Factors Contributing to Performance Difference," In D. Gerver and H.W. Sinaiko (Eds.), Language Interpretation and Communication, New York: Plenum Press, pp. 273-288.

MacWhinney, B. (1997): "Simultaneous Interpretation and the Competition Model," In J.H. Danks, G. M. Shreve, G. M. Fountain and M. K. McBeath (Eds.), Cognitive Processes in Translation and Interpreting, London: Sage Publications, pp. 215-232.

Moser-Mercer, B. (1997): “Beyond Curiosity: Can Interpreting Research Meet the Challenge?," In J.H. Danks, G.M. Shreve, G.M. Fountain and M.K. McBeath (Eds.), Cognitive Processes in Translation and Interpreting, London: Sage Publications, 176-195.

Moser, P. (1996): “Expectations of Users of Conference Interpretation," Interpreting, 1-2, pp. 145178.

Оваnа, Y. (1993): “The Linguistic Significance of Lexical Items in the Case of Conference Interpretation from English to Japanese," META, 38-3, pp. 491-501.

Schweda-Nicholson, N. (1987): "Linguistic and Extralinguistic Aspects of Simultaneous Interpretation," Applied Linguistics, 8-2, pp. 194-205.

Seleskovitch, D. (1978): Interpreting for International Conferences, Washington D.C.: Pen and Booth.

Setton, R. (1999): Simultaneous Interpretation: A Cognitive-Pragmatic Analysis, Amsterdam: John Benjamins Publishing Co.

Slobin, D. (1979): Psycholinguistics, Glenview (Ill), Scott, Foresman and Company.

Uсніуама, H. (1991): "Problems Caused by Word Order When Interpreting /Translating from English into Japanese: The Effect of the Use of Inanimate Subjects in English," META, 36-2/ 3, pp. 405-414.

VAN DAM, I.M. (1986): "Strategy of Simultaneous Interpretation: A Methodology for the Training of Simultaneous Interpreter," In K.M. Kummer (Eds.), Building Bridges: Proceedings of the 27th Annual Conference of the American Translators Association, Medford, NJ: Learned Information, Inc., pp. 441-456.

WeLLER, G. (1990): “The Influence of Comprehension Input on Simultaneous Interpreter's Output," Proceedings of the 12th World Congress of FIT, pp. 391-401.

Zahaner, C. (1990): "The Role of the Memory in Teaching Liaison Interpreting," Multilingua. DIALOG(R) File 36: Ling. and Lang. Behab. Abs(c)1994 Sociological Abstr. Inc. 